\title{
THE EFFECT OF SPACING AND THINNING ON THE YIELD OF CINCHONA LEDGERIANA
}

\author{
K. EBES
}

(Senior Lecturer in Tropical Agriculture, University College, Ibadan, Nigeria. Formerly, Agronomist \& Plant Breeder for Cinchona at West Java Experimental

Station, Buitenzorg, Java)

\section{AUTHOR's sUMmary}

The lay-out of an experiment, planned for 25 years, is described and the results of the first six checkings (the last at an age of nearly nine years) are given.

From an investigation made by SPRuIr in 1928 on the change in the number of trees in a Cinchona plantation according to their age, a preliminary conclusion was drawn that the mean average of space of a tree increases yearly by a constant amount of about 0.523 sq. metre.

In that investigation, carried out at the Government Cinchona Estate, „Tjinjiroean" near Bandoeng, Java, data were collected from plantations of different site quality and planted with different clones. The yields were mostly unknown. The incompleteness of data led to setting up an experiment to check the influence of spacing on the yield per ha.

\section{ThE LAYOUT OF THE EXPERIMENT}

As a result of preliminary investigation, SPRUIT evolved the following formula :

$$
Y=\frac{10000}{(x-a) b}
$$

where $\mathrm{Y}=$ the number of trees per ha at the age $\mathrm{x}$ ( $\mathrm{x}$ between 3.5 and 25 years). $\mathrm{a}=$ constant, to indicate a correction for the fact that a plant does not shoot up immediately after planting.

$\mathrm{b}=$ constant, to indicate the annual increase of space.

The experiment was laid out by Sprurt in 1933. It consisted of six different spacings, each spacing with grafts of the clones Tjib 5 and Tjib 1 on succirubra rootstocks, with nine replications of each clone, giving a total of 108 sample plots. The selected test-area allowed $18 \times 18 \mathrm{~m}$ for each plot.

Since the aim of the experiment was to investigate the effect of space on the yield per ha, the following different values were chosen for the constant $\mathrm{b}-0.348,0.417,0.500,0.600,0.720$ and 0.864 sq. $\mathrm{m}$. These values form a geometrical progression in the ratio of $1: 1.2$.

For this reason 12593,10370,8642,7222, 6010 and 5023, were chosen as the starting number of trees per ha. These numbers of trees form almost a geometrical progression in the ratio of $1 / 1.2$ so that the requirement of space at planting was proportional to the annual increase of the space requirement.

For the constant $a$, the following values were chosen, partly on basis of experience, partly for practical considerations : 0.578, 0.694, 0.833, 1, 1.2 and 1.44 years; that is to say the less plants per ha the longer it will take for the planting to shoot up. For the different cases we obtain the following numbers per plot and the following formulae for thinning : 


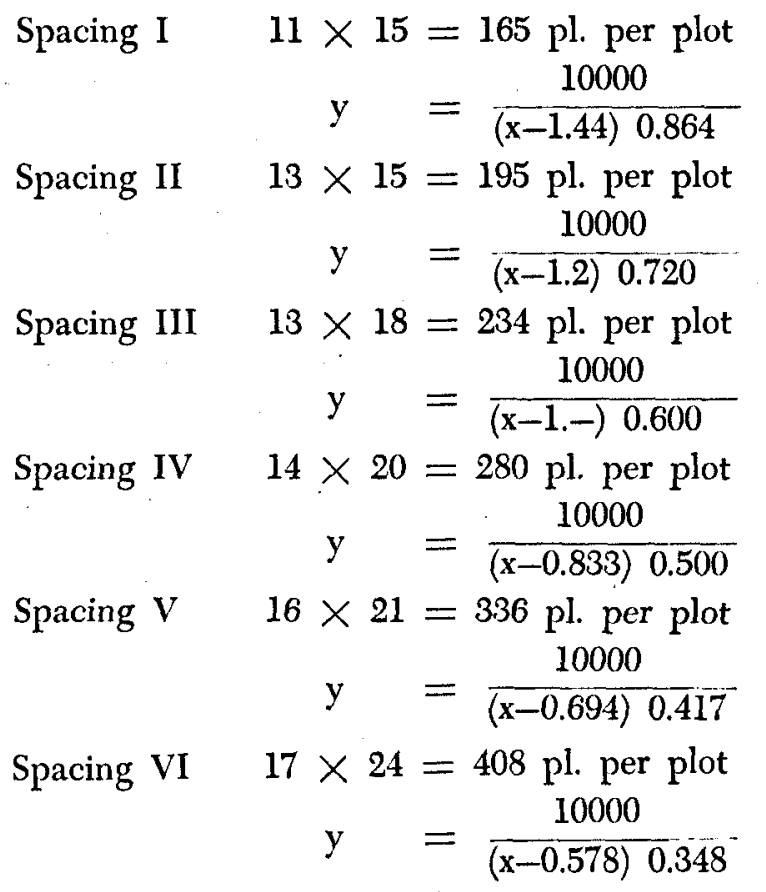

By means of these thinning formulae, the number of trees which were to be lifted annually were calculated. The results of these calculations are to be found in table $\mathrm{A}$.

Further, by means of a small tree-map of one of the plots of each spacing, the number of trees to be thinned each year was distributed as evenly as possible over the plots. So in the first place attention was not given to the growth or outward appearance of the tree to be thinned, but to its position in the plot.

\section{Procedure of the experiment}

As already mentioned the test-area allowed a plotsize of $18 \times 18 \mathrm{~m}$; the area was set out in a rectangle of $6 \times 18$ plots. The plots of Tjin 1 , and those of Tjib 5 alternated in every direction, while the spacing also differed regularly, lengthwise and breadthwise in the area. Thus the nine repetitions of each object and of each clone were scattered over the test-area as systematically as possible. The soil was a sandy loam of moderate quality, and used for cinchona since 1880. To secure a good development of the planting, the plantation was fertilized regularly with $100 \mathrm{~kg}$ of nitrogen (in the form of urea), and $40 \mathrm{~kg}$ of phosphoric acid (in the form of double superphosphate) per year and per ha. The development of the plantation up to 1942 has been satisfactory.

The experiment was set up in February 1933, and the densest planting (12593 trees per ha) was thinned for the first time in October 1935. Simultaneously all other plots were pruned. Further, they were thinned each year and pruned in April, 1937, 1938 and 1940.

During every thinning in October the number of trees in each plot was counted. The thinned trees were marked and measured as follows; the girth 


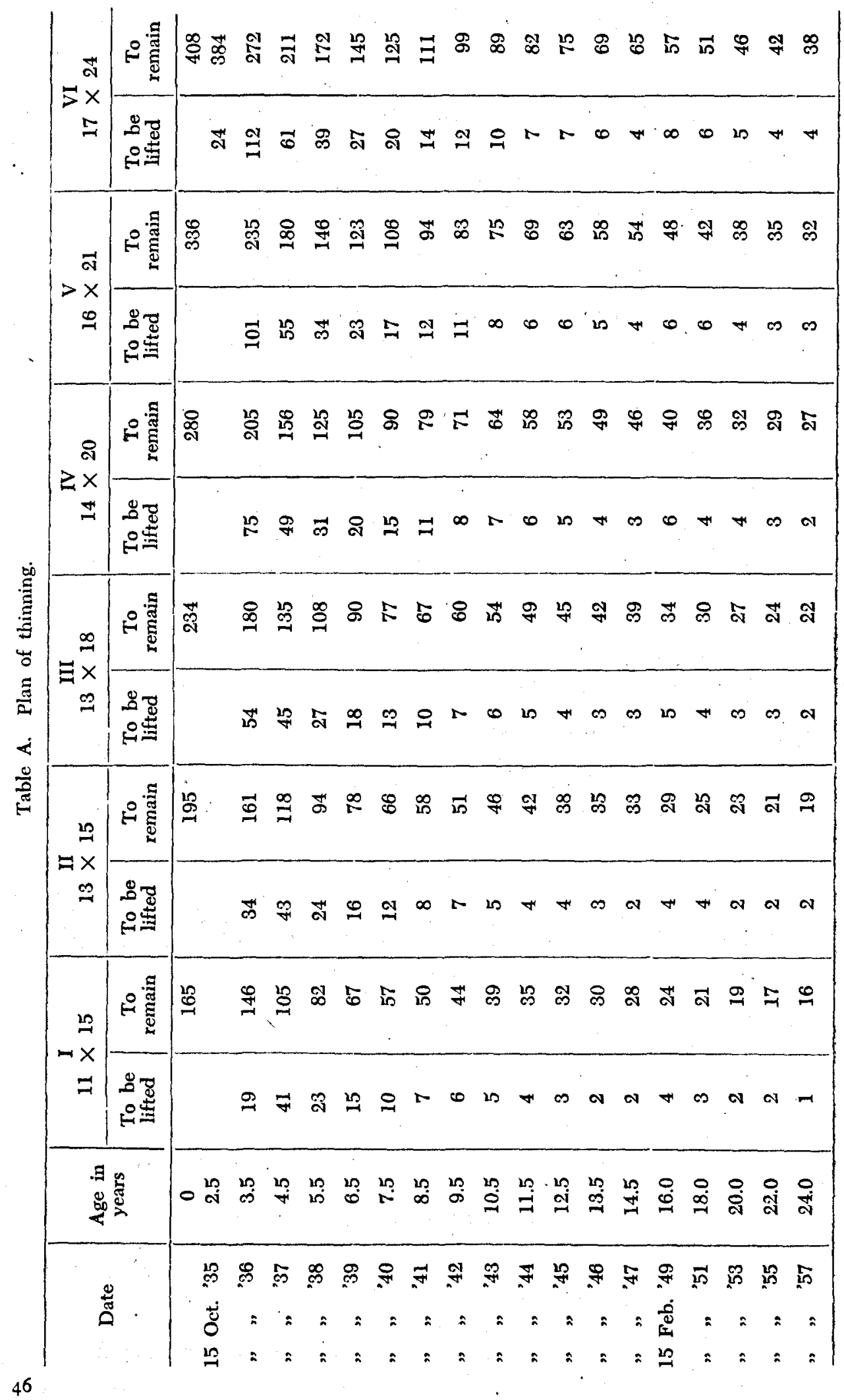


at a level of one metre from the ground and the thickness of the bark. In addition a bark sample was cut from every tree and the bark samples of the trees of the same spacing were analysed together to estimate the ring contents of quinine of the thinning stand.

The thinned trees were then lifted, the yield of wet bark was determined for each plot, and this was then separated into bark and root bark. Barks of plots of the same spacing were dried together, weighed, sampled and analysed. Further, the girth and thickness of the bark of the remaining stand were measured, tree by tree and plot by plot, and since 1939 the height of each tree as well.

By means of the data obtained at thinning it was possible to calculate production of bark and quinine sulphate per tree and per ha for the different spacings.

The calculations of the production per ha were made in two different ways : 1 by the yield per tree which was multiplied by the number of trees per ha, 2 by the surface area at the base.

On the basis of an earlier investigation it was assumed that the yield of bark of cinchona trees of the same age, the same clone, and grown under the same circumstances is about proportional to their surface area at the base of the tree i.e. the area of the transverse section of the trunk at one metre. From the total of the base surfaces of the thinned trees and their bark yield, the quantity of the bark per unit of base surface i.e. sq.m. was calculated. By multiplying the base surface of the remaining stand with the quantity of bark per sq. $m$. base surface, the stock of the bark of the remaining stand was found. The results of both manners of calculation coincided fairly well.

\section{Results OF THE FIRST SIX CHECKINGS}

The results of the first six checkings are to be found in 18 tables which are added to this paper. They contain the following data:

$a$ Of the production

1 Total production of ledger-bark.

2 Total production of root bark.

3 Total production of quinine sulphate.

4 Average annual production of quinine sulphate, from the date of planting.

5 Pruning and thinning yield of ledger bark.

6 Total pruning and thinning yield in quinine.

7 Stock of quinine sulphate directly after thinning.

8 Total production of quinine sulphate in percentage of the average.

$b$ Of the stand

9 Number of trees of the remaining stand.

10 Number of trees to be thinned.

11 Average height.

12 Average girth.

13 Average thickness of the bark.

14 Percentage thickness of the bark.

15 Bark yield per tree.

16 Yield of quinine sulphate per tree.

17 Contents of the ledger bark.

18 Ring contents of quinine, waterfree at $1 \mathrm{~m}$.

From the production data the following may be stated: 
The production of Tjib 5 is about $20 \%$ higher than that of Tjin 1 . The plantings of about 7200 and 8600 per ha have produced less than the widestspaced plantings of about 5000 per ha and also less than the narrowest spaced planting of about 12600 per ha. The difference in yield between the plots of very different spacings is relatively small (Table 8). This could a priori be expected: there must be a relation between the production per ha and the total surface of the leaves of the trees present on the hectare. A maximum production will be found at a maximum surface of the leaves, that is when the canopy of the plantation is completely closed. This was the case with all 6 spacings, the difference of the extremes being only big crowns on a small number of trees against small crowns on a large number of trees.

The plots with the densest stand of Tjib 5 as well as of Tjin 1 have given the greatest average production of quinine sulphate.

Whether this greater yield is of financial profit depends on the costs of planting material and of planting, and also the price of quinine sulphate.

From a technical point of view, narrow spacing has advantages as well as disadvantages : one advantage is that it is easier to thin a densely spaced plot than a widely spaced one, especially when the trees are older. Also pruning is not so difficult and general upkeep easier. However, narrow spacing has a disadvantage since it may make a heavy demand on the soil. Attention should be paid to the fact that the testing plot was fertilized every year with $100 \mathrm{~kg}$ nitrogen and $40 \mathrm{~kg}$ phosphoric acid per ha.

In Table 11 the average height of the six spacings is given. From this table it is evident that the height is practically independent of spacing, by contrast with the girth (Table 12) which is a function of it.

Table 14 gives the "percentage" thickness of the bark. By percentage thickness of the bark is meant the thickness of bark expressed in percentage of the radius. The percentage thickness of the bark is therefore a relative measure of the thickness of the bark. It appears from the table that in the most densely planted plots the bark is relatively thick.

In practice the opposite is believed, namely, that narrow spaced cinchona should give very thin bark. This is correct in itself, as narrow spacing produces slender trees with thin bark, but relatively, these barks are not thinner than those of wide spaced trees.

In tables 17 and 18 are given quinine contents.

The average content of the ledger bark has a slight tendency to decrease with the age as well as with the spacing. This tendency is most clearly shown in the figures for the ring content of quinine (content of pure quinine in absolutely dry bark from a sample cut one metre above the ground). This content had already reached its maximum in its sixth year. The maximum decreases obviously when spacing becomes narrower.

The experiment was planned for a period of 25 years, and it is regretted that the Japanese occupation of Indonesia 1942-'45 and the revolution for independence thereafter made scientific work in Indonesia impossible. The experiment therefore, was not completed and the results only permit a preliminary conclusion, namely, with regular thinning and regular fertilization, narrow spacing of cinchona is technically preferable and gives the highest yield.

\section{REFERENCES}

SPRUIT, P. P.zN. C., Over de verandering van het aantal boomen per oppervlakte-eenheid met den leeftijd, Cinchona 5 (1928) 34. 


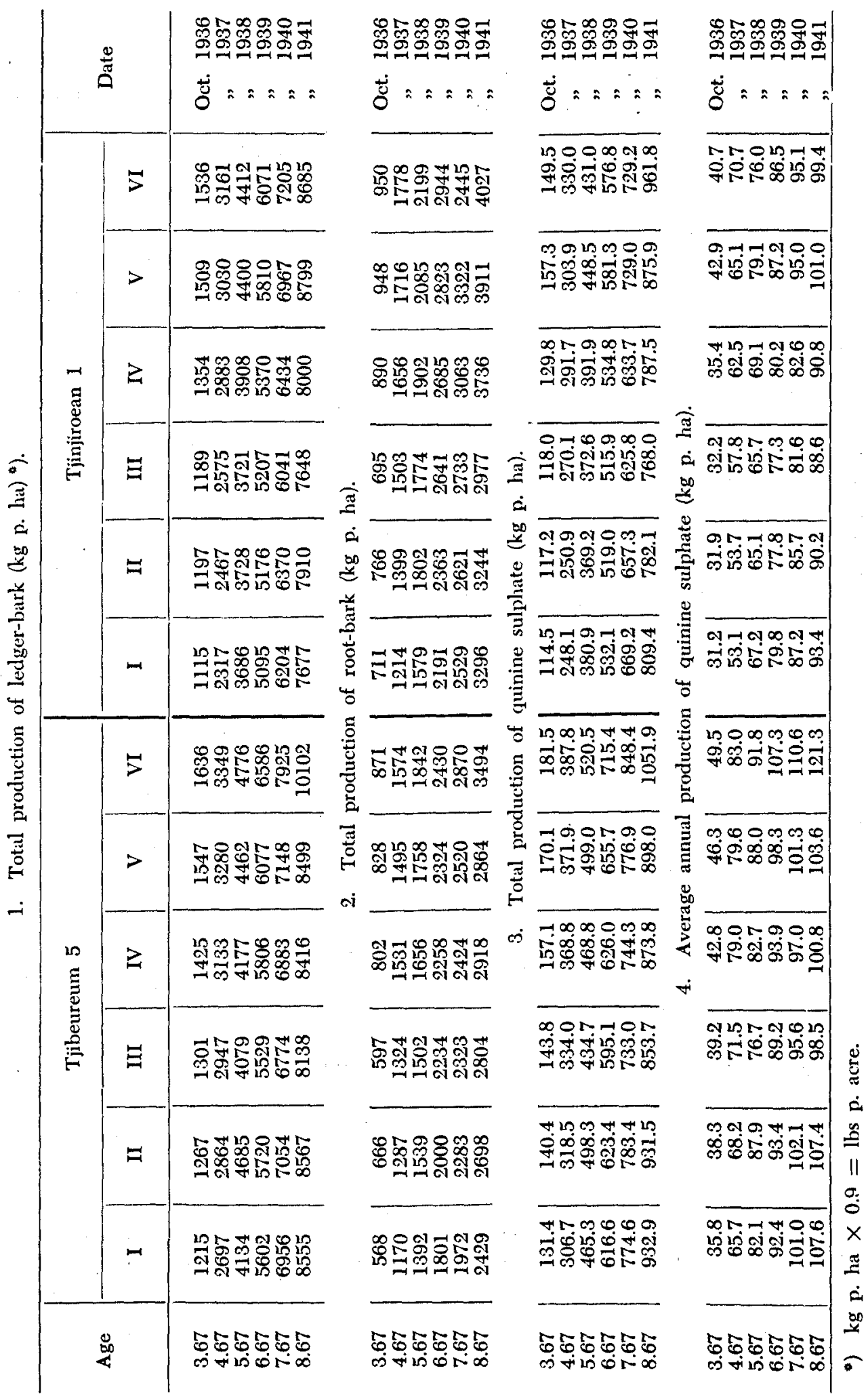




\begin{tabular}{|c|c|c|c|c|}
\hline \multicolumn{2}{|c|}{ 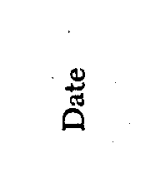 } & 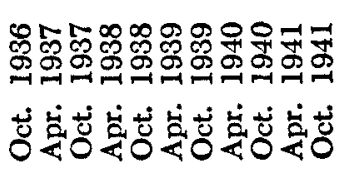 & 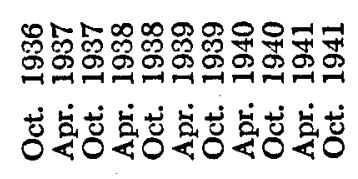 & 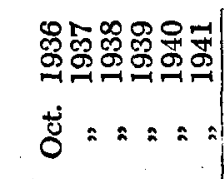 \\
\hline \multirow{6}{*}{ 俤 } & 5 & 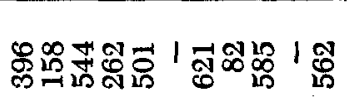 & 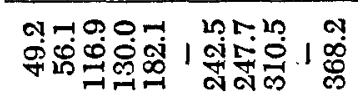 & 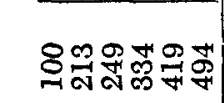 \\
\hline & $>$ & 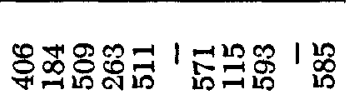 & 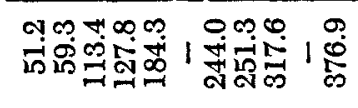 & 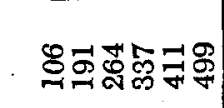 \\
\hline & $z$ & 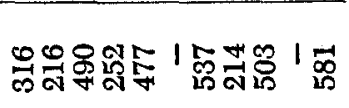 & 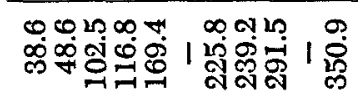 & 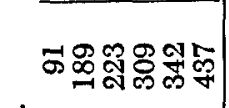 \\
\hline & $\Xi$ & 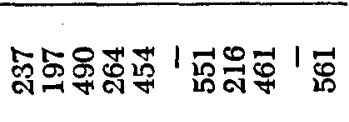 & 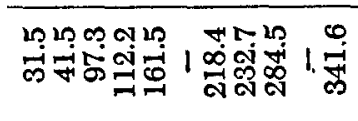 & 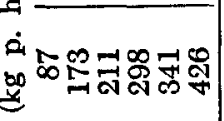 \\
\hline & $\approx$ & 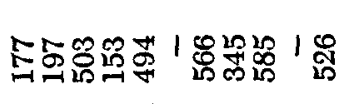 & 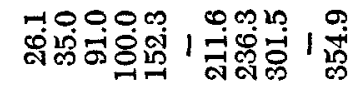 & 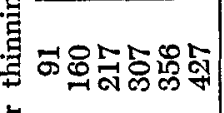 \\
\hline & $\sim$ & 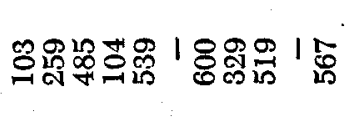 & 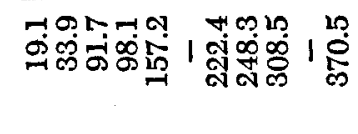 & 를 \\
\hline \multirow{6}{*}{ 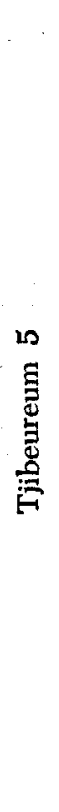 } & 5 & 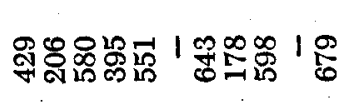 & 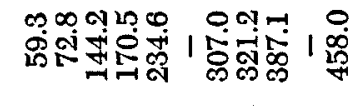 & 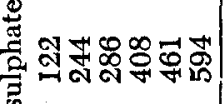 \\
\hline & $>$ & 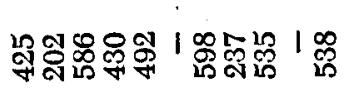 & 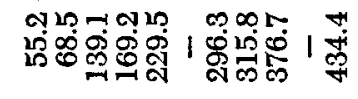 & 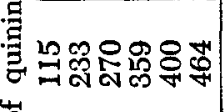 \\
\hline & Z & 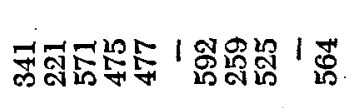 & 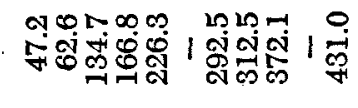 & 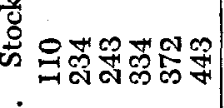 \\
\hline & $\Xi$ & 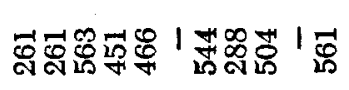 & 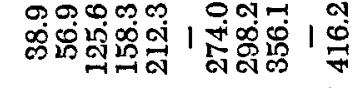 & 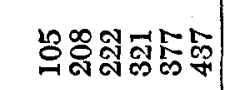 \\
\hline & $\approx$ & 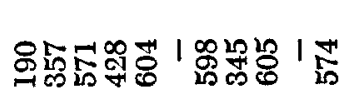 & 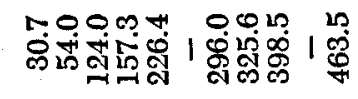 & 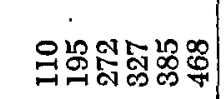 \\
\hline & $\pi$ & 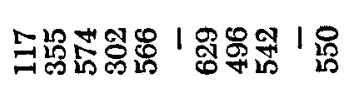 & 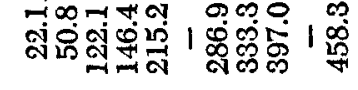 & 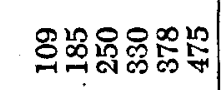 \\
\hline & & 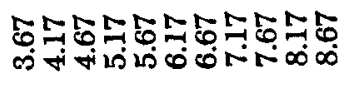 & 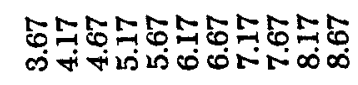 & 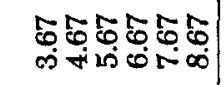 \\
\hline
\end{tabular}




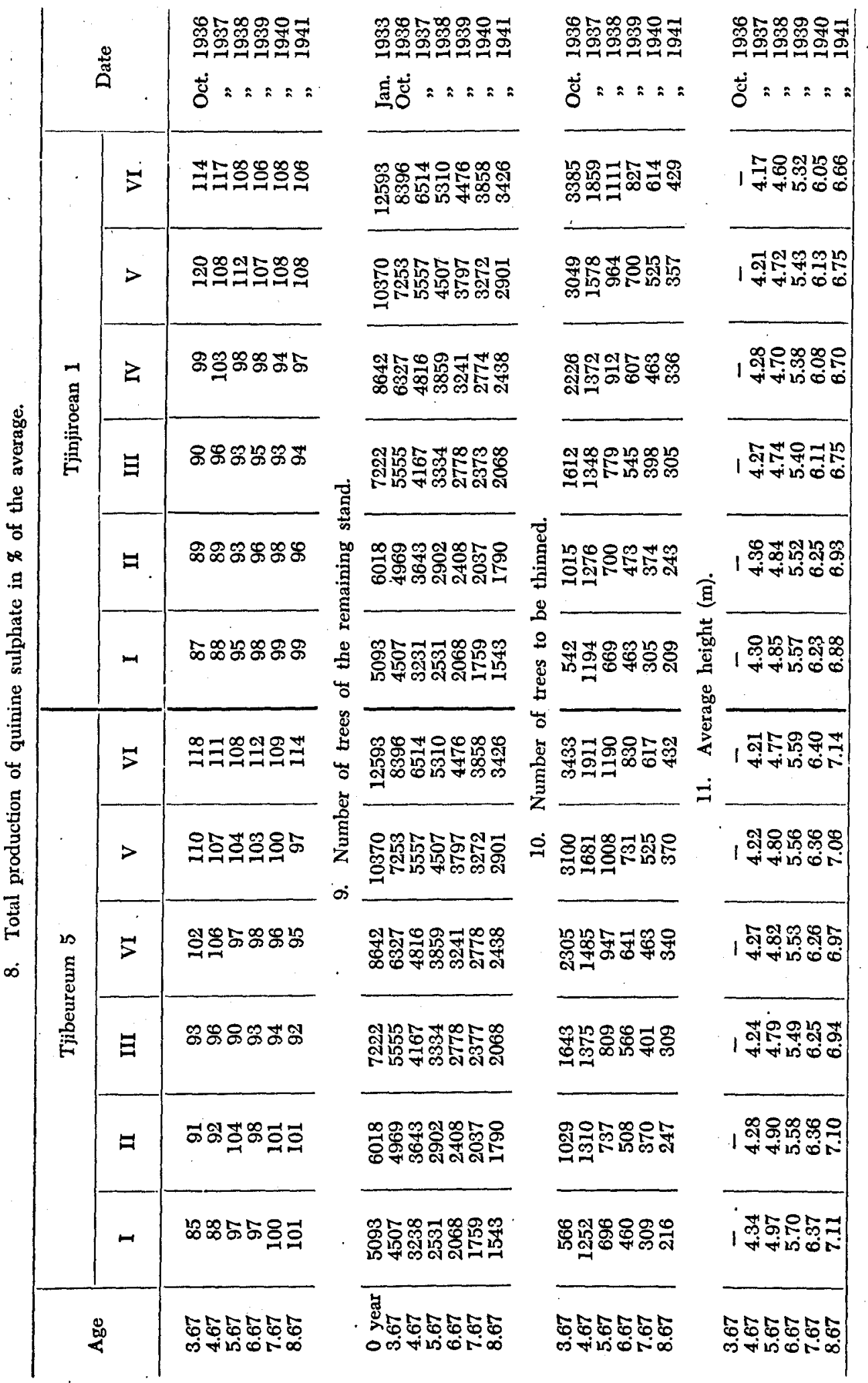




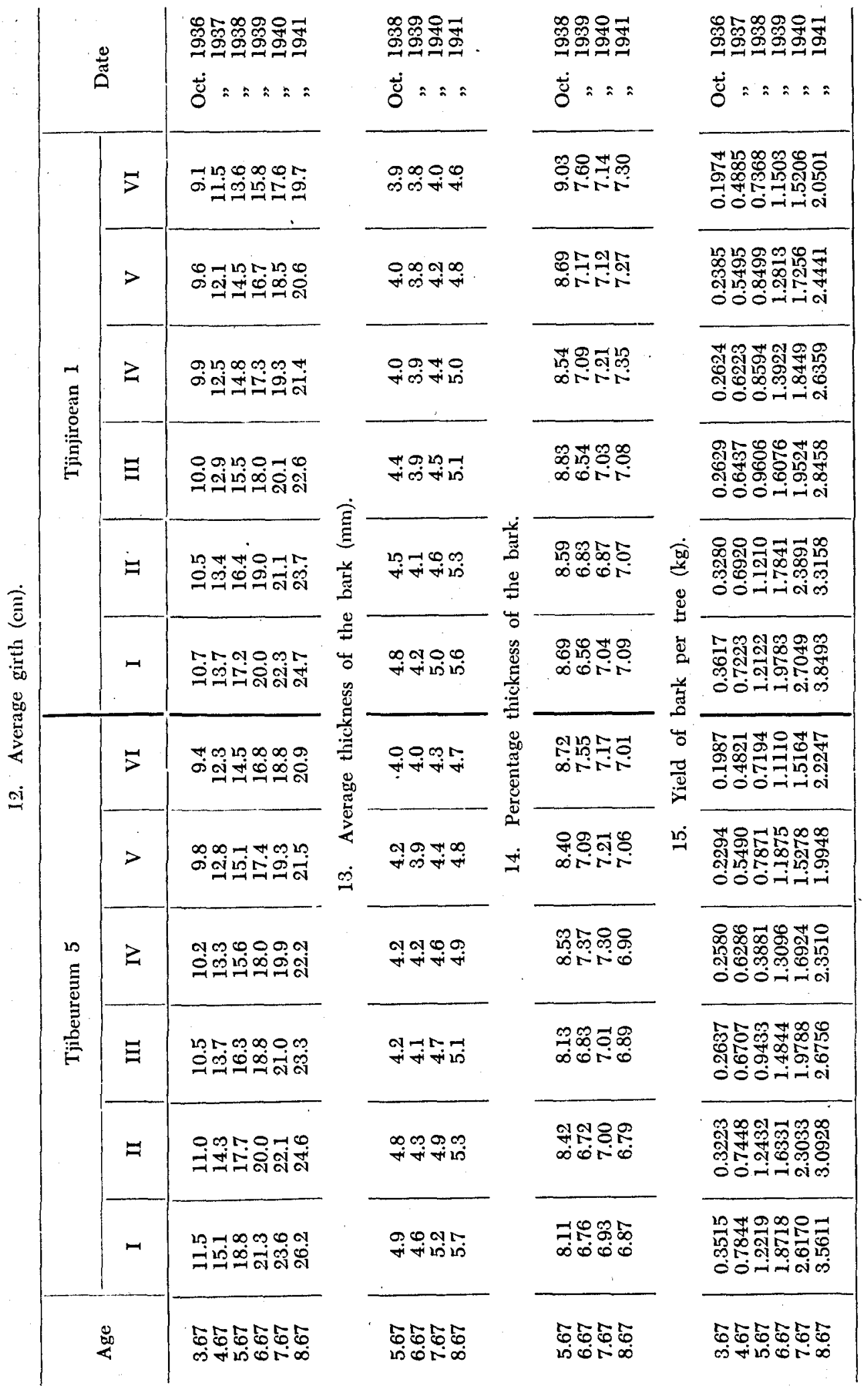




\begin{tabular}{|c|c|c|c|c|}
\hline \multicolumn{2}{|c|}{ ڤัँ } & 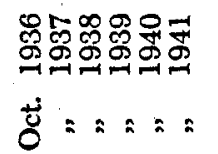 & 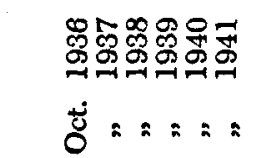 & 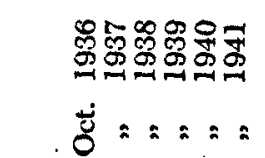 \\
\hline \multirow{6}{*}{ 島 } & 5 & 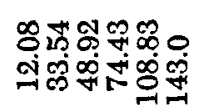 & 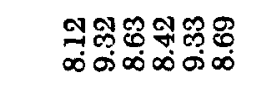 & 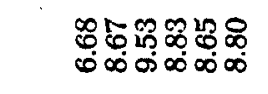 \\
\hline & $>$ & 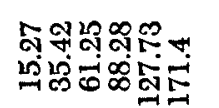 & 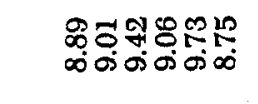 & 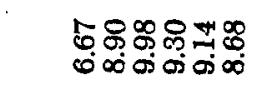 \\
\hline & $Z$ & 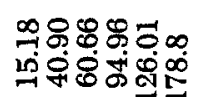 & 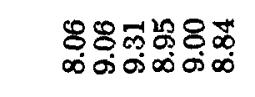 & 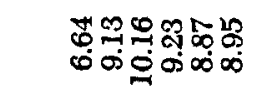 \\
\hline & $\Xi$ & 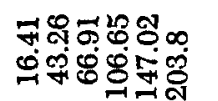 & 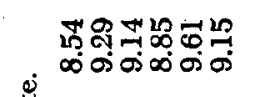 & 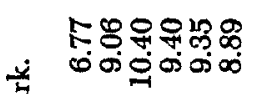 \\
\hline & $\exists$ & 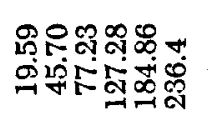 & 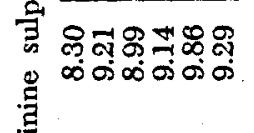 & 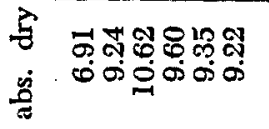 \\
\hline & 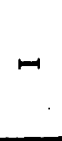 & 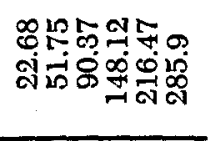 & 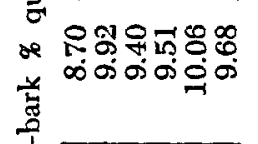 & 题 \\
\hline \multirow{6}{*}{ 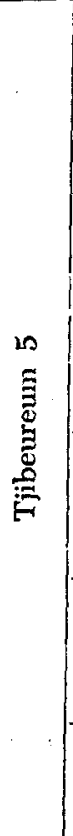 } & 5 & 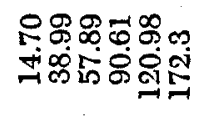 & 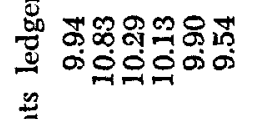 & 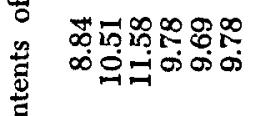 \\
\hline & $>$ & 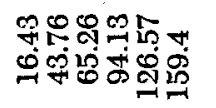 & 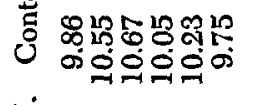 & 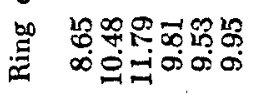 \\
\hline & 2 & 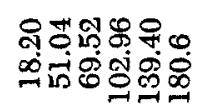 & 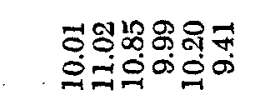 & 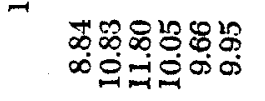 \\
\hline & $\Xi$ & 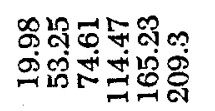 & 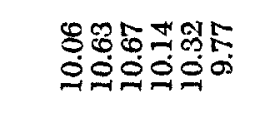 & 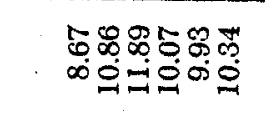 \\
\hline & $\Xi$ & 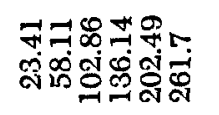 & 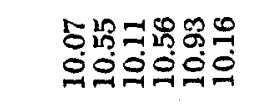 & 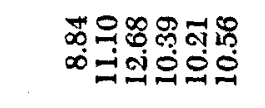 \\
\hline & $r$ & 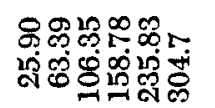 & 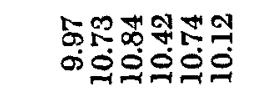 & 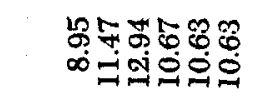 \\
\hline$\sum_{4}^{a}$ & & 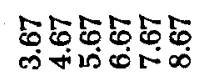 & 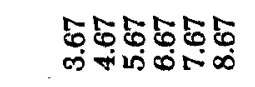 & 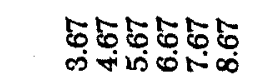 \\
\hline
\end{tabular}

